\title{
The Spectrum Captured: A Methodological Approach to Studying Incidence and Outcomes of Traumatic Brain Injury on a Population Level
}

\author{
A. Theadom $^{a} \quad$ S. Barker-Collo ${ }^{b} \quad$ V.L. Feigin ${ }^{a} \quad$ N.J. Starkey ${ }^{e}$ K. Jones ${ }^{a} \quad$ A. Jones ${ }^{a}$ \\ S. Ameratungac P.A. Barber ${ }^{d}$ on behalf of the BIONIC Research Group ${ }^{1}$ \\ a National Institute for Stroke and Applied Neuroscience, School of Rehabilitation and Occupation Studies,

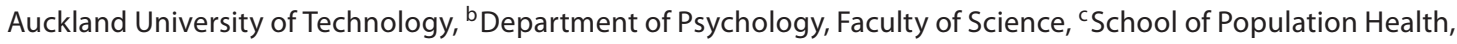 \\ and ${ }^{\mathrm{d}}$ Department of Medicine, University of Auckland, Auckland, and ${ }^{\mathrm{e}}$ School of Psychology, Faculty of Arts and \\ Social Sciences, University of Waikato, Hamilton, New Zealand
}

\section{Key Words}

Traumatic brain injury $\cdot$ Epidemiology $\cdot$ Longitudinal . Outcomes • Assessment $\cdot$ Methods $\cdot$ New Zealand · Incidence

\begin{abstract}
Objective: Drawing on the experience of conducting the Brain Injury Incidence and Outcomes New Zealand in the Community study, this article aims to identify the issues arising from the implementation of proposed guidelines for population-based studies of incidence and outcomes in traumatic brain injury (TBI). Study Design and Setting: All new cases of TBI (all ages and severities) were ascertained over a 1-year period, using overlapping prospective and retrospective sources of case ascertainment in New Zealand. All eligible TBI cases were invited to participate in a comprehensive assessment at baseline and at 1-month follow-up. $\boldsymbol{R e}$ sults: Our experience to date has revealed the feasibility of case ascertainment methods. Consultation with community health services and professionals resulted in feasible referral pathways to support the identification of TBI cases. 'Hot pursuit' methods of recruitment were essential to ensure complete case ascertainment for this population with few ad-
\end{abstract}

ditional cases of TBI identified through cross-checks. Conclusion: This review of proposed guidelines in relation to practical study methodology provides a framework for future comparable population-based epidemiological studies of TBI incidence and outcomes in developed countries.

Copyright $\odot 2011$ S. Karger AG, Basel

\section{Introduction}

Traumatic brain injury (TBI) is a leading cause of disability and death in children and young adults [1-3]. TBI has enormous personal, economic and social consequences, including difficulties maintaining social relationships, returning to work/study and integration into the community [4-7]. The direct and indirect costs of TBI

\footnotetext{
The BIONIC Research Group, who contributed to this article and the BIONIC study: Prof. Valery Feigin (Chair), Dr. Suzanne Barker-Collo, Prof. Kathryn McPherson, Prof. Robert Kydd, Prof. P. Alan Barber, Ms Varsha Parag, Dr. Paul Brown, Dr. Nicola Starkey, Prof. Anthony Dowell, Dr. Michael Kahan, Dr. Alice Theadom, Associate Prof. Shanthi Ameratunga, Dr. Grant Christey, Mr. Tai Kake, Dr. Kris Fernando, Prof. Ross Lawrenson, Dr. Kelly Jones, Ms Amy Jones.
}

\section{KARGER}

Fax +41613061234 E-Mail karger@karger.ch www.karger.com
(C) 2011 S. Karger AG, Base

0251-5350/12/0381-0018\$38.00/0

Accessible online at:

www.karger.com/ned
Dr. Alice Theadom, National Institute for Stroke and Applied Neuroscience School of Rehabilitation and Occupation Studies

Faculty of Health and Environmental Sciences, AUT North Shore Campus, AA254C 90 Akoranga Drive, Private Bag 92006, Auckland 1142 (New Zealand)

Tel. +649921 9999, ext. 7805, E-Mail alice.theadom@aut.ac.nz 
Table 1. Suggested guidelines for population-based studies of TBI [12]

\begin{tabular}{|c|c|c|}
\hline Domains & Core criteria & Supplementary criteria \\
\hline $\begin{array}{l}\text { Standard } \\
\text { definitions }\end{array}$ & $\begin{array}{l}\text { - World Health Organization criteria for TBI } \\
\text { diagnosis [13] } \\
\text { - First-ever-in-a-lifetime TBI } \\
\text { - TBI severity classification by GCS [14] - mild: } \\
\text { a score of } 13-15 \text {; moderate: a score of } 9-12 \text {; } \\
\text { severe: a score of } 3-8\end{array}$ & $\begin{array}{l}\text { - Recurrent TBI } \\
\text { - TBI severity classification by GCS }[14] \text { and duration of PTA } \\
\text { as determined from medical records or relevant PTA scale } \\
\text { [15, 16] - mild: a score of } 13-15 \text { and PTA }<24 \text { h; moderate: } \\
\text { a score of 9-12 and PTA } 1-6 \text { days; severe: a score of } 3-8 \text { and } \\
\text { PTA } 7+\text { days }\end{array}$ \\
\hline $\begin{array}{l}\text { Standard } \\
\text { methods }\end{array}$ & $\begin{array}{l}\text { Case ascertainment } \\
\text { - Large well-defined and stable population, } \\
\text { allowing at least 100,000 person-years of } \\
\text { observation } \\
\text { - Reliable method for estimating denominator } \\
\text { (not more than 5-year-old census data) } \\
\text { - Complete population-based case ascertain- } \\
\text { ment, based on multiple overlapping sources } \\
\text { of information (hospitals, outpatient clinics, } \\
\text { general practitioners, death certificates) } \\
\text { - Prospective study design } \\
\text { - Causes (mechanisms) of TBI recorded } \\
\text { Follow-up of cases } \\
\text { - Follow-up of patients' vital status for at least } \\
\text { 1-month }\end{array}$ & $\begin{array}{l}\text { - 'Hot pursuit' of cases } \\
\text { - Direct assessment of underascertainment by regular checking } \\
\text { of general practitioners' databases and hospital admissions for } \\
\text { acute trauma and CT/MRI investigations } \\
\text { - Follow-up of patient's functional and vital status up to } 1 \text { year } \\
\text { or longer after TBI }\end{array}$ \\
\hline $\begin{array}{l}\text { Standard data } \\
\text { presentation }\end{array}$ & $\begin{array}{l}\text { - Complete calendar years of data } \\
\text { - Men and women presented separately } \\
\text { - Mid-decade age bands (e.g. } 25-34 \text { years) } \\
\text { used in publications } \\
\text { - } 95 \% \text { confidence intervals around rates }\end{array}$ & $\begin{array}{l}\text { - Unpublished 5-year age bands available for comparison with } \\
\text { other studies }\end{array}$ \\
\hline
\end{tabular}

are high [8] and the number of disability-adjusted life years lost due to TBI is significant [9]. While people experiencing moderate and severe TBI are recognised to be at increased risk of significant levels of disability, the magnitude of the adverse consequences for those sustaining mild TBI and the resulting social ramifications and costs are often underestimated [10].

In the UK, Australia and North America, 200-300 people per 100,000 are admitted to hospital with a TBI each year [11]. Previous studies of TBI have typically utilised hospitalisation or health care service data as the basis of their estimates. These studies have not always accounted for cases of fatal TBI, or undiagnosed TBI (e.g. in situations where brain injuries are overshadowed by other conditions as a result of multiple trauma) [12]. Using these methods alone risks missing cases of mild TBI that do not present for medical attention. Cases of mild TBI account for $70-90 \%$ of all TBIs [1] and for every 100 peo- ple seen at hospital regarding TBI, it is estimated that at least 60 are seen and managed by their general practitioner (GP) alone [7]. It is therefore particularly important that TBI is examined in a population-wide context, to reveal the true incidence of TBI.

Guidelines for the conduct of population-based incidence studies in TBI have recently been proposed and are summarised in table 1 [12]. Following production of these guidelines, the study team endeavoured to conduct a population-based study of TBI incidence and outcomes: the Brain Injury Incidence and Outcomes New Zealand in the Community (BIONIC) study. This paper describes in detail the methods used in the BIONIC study through direct comparison against proposed guidelines and aims to refine the guidelines, by offering practical approaches to managing the issues encountered through implementation. 


\section{Methodology}

The methodology of the BIONIC study will be presented in direct comparison against the guidelines suggested by BarkerCollo and Feigin [12] (outlined in table 1) to illustrate how the guidelines were implemented. A review of the methodological issues arising and how they have been resolved in the BIONIC study are described and discussed under the three core components of the guidelines: standard definitions; standard methods, and standard data presentation.

\section{Standard Definitions}

\section{Confirming the Presence of Injury}

In line with the suggested guidelines, TBI was defined as 'an acute brain injury resulting from mechanical energy to the head from external physical forces. These manifestations of TBI must not be due to drugs, alcohol, medications, caused by other injuries or treatment for other injuries (e.g. systemic injuries, facial injuries or intubation), caused by other problems (e.g. psychological trauma, language barrier or coexisting medical conditions)', as defined by the World Health Organization [13, p. 115]. All TBIs occurring in the 12-month case ascertainment period (1st March 2010 to 28th February 2011) within both children and adults were recorded. Based on recent analysis of New Zealand TBI hospitalisation data (1997-2004) [17] and assuming the TBI incidence rate is about $600 / 100,000$ people per year, as suggested by the New Zealand TBI Guidelines [7], the study team conservatively estimated 1,039 new TBI events during the 1-year case registration period. This sample size was deemed to be sufficient to obtain reliable age-, sex- and ethnic-specific incidence estimates for urban (Hamilton city) and rural (Waikato district) study populations, as suggested by the proposed guidelines [12]. Information was only collected for people who experienced a new TBI event during the case ascertainment period, with selfreport data on recurrent and prior TBIs collected at baseline and follow-up to enable calculation of first-ever-in-a-lifetime rates of TBI and recurrent TBIs collected during the follow-up assessment.

To ensure complete case ascertainment, all cases of TBI, including those who had not presented to hospital or those who attended for medical care after an accident indicating that a TBI may have occurred, were identified and investigated. For these participants, it was important to be able to confirm whether a TBI had occurred and if the participant met the study criteria for inclusion. To confirm each case, all potential participants were contacted by a researcher and asked: (1) if they had lost consciousness (or were knocked out); (2) if they had been dazed or confused or had 'seen stars' at the time of injury, or (3) if they could not remember the injury or if they had experienced any memory problems since their injury as previously recommended [18]. Participants only needed to answer yes to 1 of the 3 questions with a description of an accident likely to lead to a TBI, in order to be classified as having experienced a TBI. The study criteria also required participants to have lived (or have been registered) at an address within the study area for at least 12 months.

\section{Injury Severity}

TBI severity was classified based on the Glasgow Coma Scale (GCS) [14] and Posttraumatic Amnesia (PTA) scores [19] as suggested in the supplementary criteria of the guidelines. At times there was discordance between the two scores. In these cases, the more severe category was assigned [7]. Participants who did not have a GCS or PTA score recorded in their medical notes were classified as having a mild TBI. This was because people who were most likely to have had a moderate or severe brain injury would have been seen by the ambulance service or they would have attended a primary or secondary health care service (where GCS was routinely recorded).

Due to the wide spectrum of outcomes from TBI [20], and because it was anticipated that approximately $90 \%$ of cases would be mild TBI, a way of distinguishing between mild cases was needed. Individuals were classified as having 'low-risk', 'mild-risk' and high-risk' complications as proposed by Servadei et al. [21].

Weekly study-specific meetings consisting of a neurologist (V.F.), a neuropsychologist (S.B.-C.) and other allied health professionals were established to oversee the running of the project, review recruitment numbers, ensure the scientific rigour of the study procedures and to review the eligibility of participants. All cases where the presence or severity of injury was unclear, or that may have only been considered for inclusion in the study based on an altered consciousness where there was evidence of alcohol or other substances, were presented and discussed at this meeting to determine their appropriate diagnostic category and inclusion or exclusion. Cases where there was unclear evidence of a TBI or where altered consciousness was unlikely to have been caused by the injury were not registered to avoid overidentification of TBI cases.

In the BIONIC study, children were classified as those aged $<16$ years. On review of available criteria for determining TBI severity of children, it became evident that research has previously applied adult TBI severity criteria using GCS and PTA scores, suggesting that there is no standard criterion for severity of TBI designed specifically for children. For this study, the only difference in classifying TBI severity in children (as compared to adults) was that evidence of a skull fracture meant that the injury was classified as at least a moderate injury as recommended [22]. If no GCS score was available for a child, parental reports/legal guardian reports of changes in behaviour were solicited with an emphasis on observed behaviours. For a case to be registered as a brain injury without a GCS score, children needed to have demonstrated evidence of a head injury accompanied by other medical/behavioural changes immediately following the injury including: vomiting, lethargy, persistent crying, being very quiet (out of character), irritable, refusing food, sleepiness, seizures, disorientation, unequal pupil size, headache, complaining and/or described as being 'out of sorts'.

\section{Standard Methods}

\section{Case Ascertainment}

The BIONIC study was undertaken in the Hamilton and Waikato districts of New Zealand (fig. 1), a large, well-defined population with boundaries specified by the government for local council districts. Census data from 2006 are available for the analysis stage of the BIONIC study to inform the calculation of incidence rates for the New Zealand population. The Hamilton and 


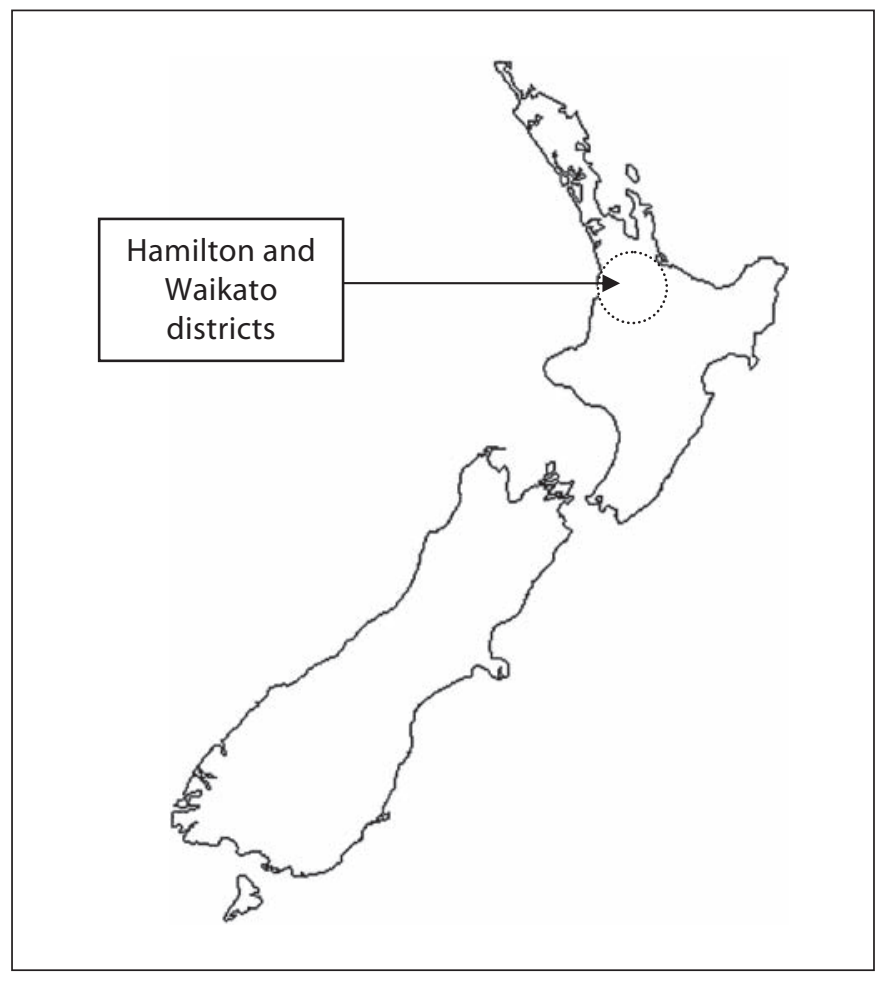

Fig. 1. Map of New Zealand showing the BIONIC study area.

Waikato districts have a population of 173,208 [23] and were selected as they have demographic and social characteristics reflective of the wider New Zealand population (i.e., age, ethnic structure, education levels, socio-economic mix) [23] and include rural and urban areas, with medical services that cover the whole spectrum of care after TBI.

A number of multiple overlapping sources of identifying eligible TBI cases needed to be established to ensure complete case ascertainment. Due to the wide age range of people experiencing TBI and the nature of the possible mechanisms of injury (e.g. motor vehicle accidents, assaults, falls), a range of community services needed to be engaged in the study in comparison to other epidemiological studies of conditions such as stroke [24]. Prior to commencement of the study, all health care providers (e.g. health centres, GPs, physiotherapists), hospital departments, ambulance services, TBI service providers, national health care databases, the local prison, death registry and community services (e.g. schools, residential facilities, sports clubs) were visited by members of the study team (table 2) to inform them about the study and to enlist their help in case identification. Discussions were held with each service to determine the most appropriate and feasible method of making referrals to the study. These procedures were established and set up prior to the start of case ascertainment and proved an essential component for ensuring accuracy and maintenance of referrals. All agencies and providers who were approached and consulted about the study agreed to assist in case identification to enable the prospective identification of TBI cases.

Methodology for Epidemiological Studies in TBI
Table 2. Procedure for case ascertainment

\begin{tabular}{|c|c|}
\hline $\begin{array}{l}\text { Frequency of } \\
\text { source checks }\end{array}$ & Source of case ascertainment \\
\hline Daily & $\begin{array}{l}\text { All admissions to the emergency departments at } \\
\text { the main local hospital }\end{array}$ \\
\hline Weekly & $\begin{array}{l}\text { Visits to community health services (GP practic- } \\
\text { es, rehabilitation/outpatient clinics/accident and } \\
\text { medical centres) to chase referrals that have not } \\
\text { been faxed/completed. Search of the local TBI } \\
\text { provider database (ABI Rehabilitation Manage- } \\
\text { ment) }\end{array}$ \\
\hline Monthly & $\begin{array}{l}\text { Hospital discharge register for hospitals on the } \\
\text { study area boundaries and specialty hospitals } \\
\text { (where patients may be transferred, e.g. Starship } \\
\text { Children's Hospital in Auckland). Checks with } \\
\text { the St John Ambulance records and local prison } \\
\text { service for any referral forms }\end{array}$ \\
\hline Quarterly & $\begin{array}{l}\text { Visits, telephone contact and/or letters to local } \\
\text { residential facilities, sports centres and schools } \\
\text { for any potential eligible cases }\end{array}$ \\
\hline Six-monthly & $\begin{array}{l}\text { Checks of patients identified by the Accident } \\
\text { Compensation Corporation (the primary source } \\
\text { of funding for treatment of all accidental injury in } \\
\text { New Zealand, including TBI) and New Zealand } \\
\text { Health Information System databases (tracking } \\
\text { all hospital admissions by diagnostic code in New } \\
\text { Zealand), coroner/autopsy records and death cer- } \\
\text { tificates }\end{array}$ \\
\hline Ongoing & $\begin{array}{l}\text { Self-referrals encouraged through advertisements } \\
\text { in the local newspaper and television, attendance } \\
\text { at community health day events, distribution of } \\
\text { the study leaflet to all community services and } \\
\text { visits to patient support services }\end{array}$ \\
\hline
\end{tabular}

Searches of Hospital Databases

To reduce burden on hospital resources, study team members (working under an honorary contract) were based in the main hospital to conduct daily searches of hospital admissions for potential new TBI cases. As TBI cases may be missed as a result of multiple trauma or misdiagnosis, the search criteria were broad and included people presenting with the following injuries: injury to head/face/neck, any mention of 'being knocked out'/unconsciousness, fractures to upper body, leg fractures, fracture not otherwise specified, multiple injuries and injuries to the hand and/or bleeding nose for people aged 16-60 (to identify possible assaults). Known terms for common mechanisms of TBI, such as motor vehicle or motorcycle accidents, bicycle injuries, falls, assaults and symptoms possibly indicative of TBI (i.e., headaches, collapse, nausea, vomiting) were also searched to uncover potential TBI cases. If medical records were available, these were then searched to check for any signs of TBI, with those cases not meet- 
ing the study criteria excluded. All potentially eligible participants were then contacted by telephone to determine if they hit their head when they were injured and if so whether they meet the TBI criteria as outline above. Those who could not be contacted by telephone were sent a compliment slip briefly outlining the study and asking them to contact the study team. Nurses in the Accident and Emergency Departments were also asked to refer patients directly to the study, although this process did not identify further patients than those already identified through the hospital admissions database.

Comparisons between cases identified through hospital case identification procedures at admission and hospital discharge lists, for all hospitals in the Waikato and Hamilton regions, have been conducted on a monthly basis. Only $1.4 \%$ of participants have been identified through the hospital discharge register that were not identified on hospital admission, supporting the value of the proposed 'hot pursuit' (prospective and ongoing 'active' identification) method [12]. The cases that were not identified through hospital admissions had been transferred from hospitals outside the study region or had sustained TBI due to falls in hospital. These people were subsequently registered and invited to participate. In some cases, contact information obtained from hospital records was incorrect and electoral rolls and local telephone databases were searched to ascertain if these cases were indeed resident within the study area to confirm eligibility for case registration.

\section{Community Health Care Professional Referrals}

A written referral scheme was developed for community health care professionals following extensive consultation that included the ambulance and local prison services. Each clinician was given an A5 size study-specific carbon copy referral pad that specified the three operational inclusion criteria at the top of the page. Clinicians were asked to tick the box(es) next to each criterion met by the patient (a copy of this referral pad is available online at http://www.nisan.aut.ac.nz/research/research-projects). A brief statement about the study was provided for the patient who was then asked to indicate if they agreed to be (a) contacted directly by the study team who would be sent information from their consultation notes, or (b) contacted by their clinician providing a copy of the consultation notes only, or if they (c) declined to pass on any information or to be contacted. Once completed, the top copy of the referral form was faxed to the study team and/ or collected directly by a member of the research team who visited each practice weekly. On receipt of a new referral, the case was registered and those participants who consented to be contacted were followed up by the study team. Vouchers for the value of approximately half the cost of a privately funded consultation were provided to clinicians outside of the hospital sector for each new referred case that has not been identified through other sources (e.g. the hospital).

\section{Self-Referrals}

Leaflets and posters about the study were displayed in community (e.g. schools), sports and health care facilities in and around the study area. The materials outlined operational criteria for participation and asked people to contact the study team if they were eligible/interested in the study. A dedicated Community Liaison Officer was appointed to maintain links with the local community, to increase awareness about the study and facili- tate recruitment of participants who chose not to seek health care services. Local and nationwide media coverage was obtained for the study including articles in patient newsletters, local newspapers and TV programmes to further increase awareness of both TBI and the study. Regular contact was also maintained with local schools, TBI health care providers, patient support groups and residential facilities as outlined in table 2 .

'Hot pursuit' methods of case ascertainment were difficult to establish in the community, due to the large number of facilities within the study area and poor recording of accidents (e.g. within schools or sports clubs). In response to this, the study team met with key staff and visited community services every 3-6 months to provide updates on study progress and to encourage active referrals from the service. Increasing awareness of the study was supported by the distribution of quarterly newsletters providing study updates to all stakeholders in the project. Encouraging selfreferrals has proven one of the greatest challenges of the study and while media coverage has generated significant public interest, no self-referrals were obtained through this method.

Cross-Checks with Service Databases

In addition to the cross-checks between hospital admissions and discharge databases, cross-checks remain ongoing with other national databases including a national accident insurance service (Accident Compensation Corporation), TBI service providers and the New Zealand Health Information Service. To monitor the effectiveness of case ascertainment, a capture-recapture approach is planned with all modes of identification of cases being recorded for each case.

This study has highlighted the importance of investing time prior to study recruitment to establish links with all health care providers and community groups to ensure feasible referral procedures, particularly for mild TBIs. Despite efforts to engage as many stakeholders as possible in the study to ensure complete case ascertainment, it is possible that some cases may remain unaccounted for: e.g. Hamilton and Waikato residents that were injured and/or received follow-up treatment outside of the study region (such as military personnel deployed overseas), cases where the person was homeless and not known to the local services to confirm residence in the study area, or cases where the persons may not have realised that they had experienced a TBI [25]. Following identification, the eligibility of each case was checked against the study criteria outlined above and registered. Information on age, gender, ethnicity and medical details of the TBI (including cause of the TBI) was collected for all identified eligible cases.

\section{Follow-Up of TBI Cases}

Following registration, cases were assigned to a clinical researcher who contacted the participants (fig. 2), invited them to participate in the follow-up assessment component of the study and monitored outcomes after TBI. All those eligible to participate in the follow-up received an information pack in the mail and were contacted by telephone to determine their willingness to participate in assessments conducted at baseline and 1-month follow-up (table 3). Participants who were able to provide informed consent were invited to participate in the follow-up component of the study. For those who were unable to consent due to medical reasons, a proxy (defined as someone who spends a substantial part of the day with the person) was approached to ask if they 


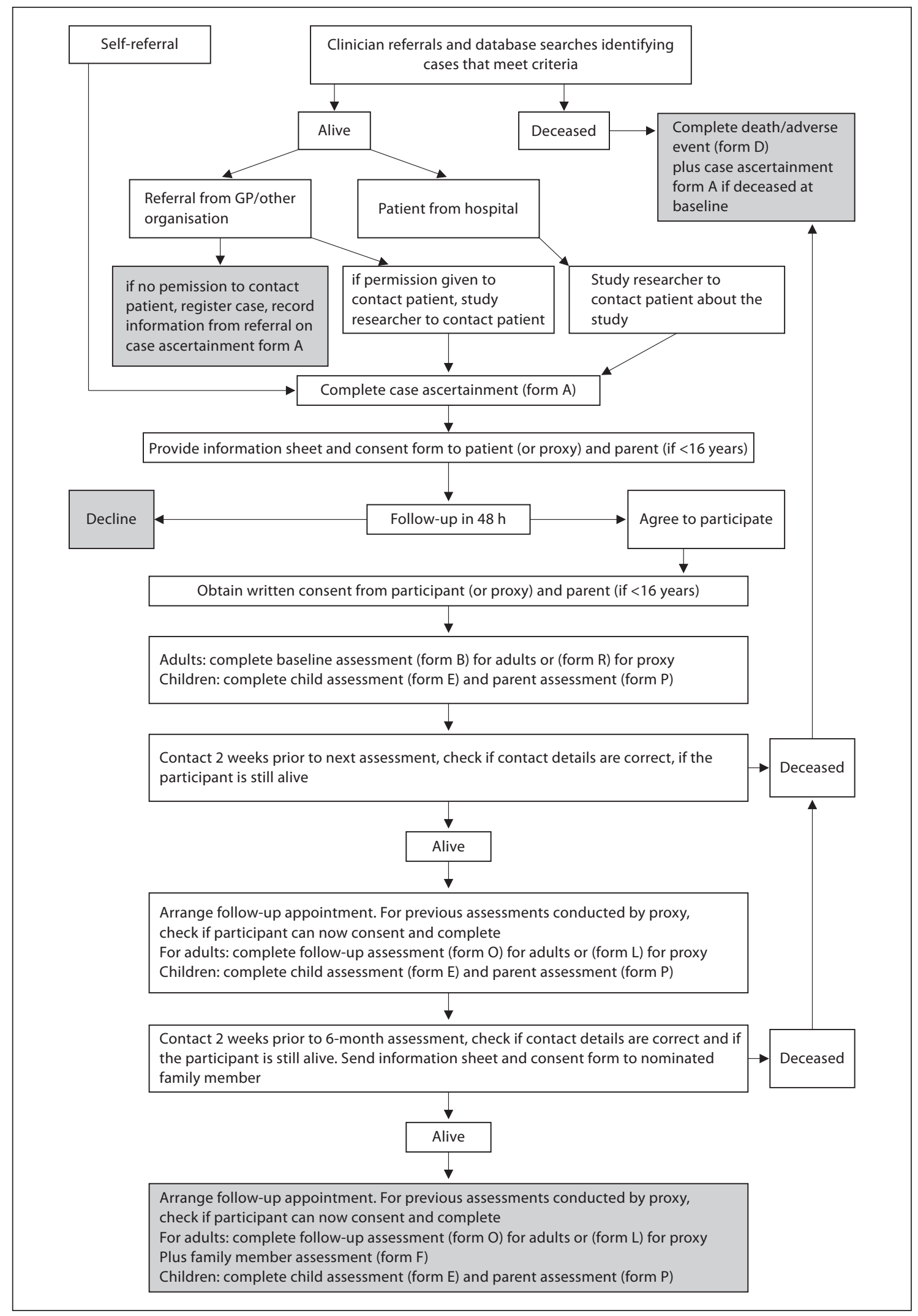

Fig. 2. Study procedures after case notification. 
Table 3. Outcome assessments in the BIONIC study

\begin{tabular}{|c|c|c|}
\hline & & Age range \\
\hline $\begin{array}{l}\text { Baseline assessment only } \\
\text { Demographic }^{1}\end{array}$ & $\begin{array}{l}\text { Age, gender, ethnicity, date and time of injury, date of first } \\
\text { presentation of injury, brain injury characteristics, co-morbidities } \\
\text { (e.g. associated injuries, diagnostic tests) }\end{array}$ & All \\
\hline \multirow[t]{2}{*}{ Injury severity ${ }^{1}$} & $\begin{array}{l}\text { GCS [14]: assessment of level of consciousness within } 24 \mathrm{~h} \text { of injury } \\
\text { Posttraumatic amnesia as measured by the Westmead PTA Scale } \\
\text { [16] assessing orientation and memory }\end{array}$ & $\geq 16$ years \\
\hline & $\begin{array}{l}\text { Paediatric Coma Scale }[26,27] \text { : assessment of level of } \\
\text { consciousness within } 24 \text { h of injury }\end{array}$ & $<16$ years \\
\hline \multirow[t]{2}{*}{$\begin{array}{l}\text { Follow-up assessments } \\
\text { Demographics }{ }^{1}\end{array}$} & $\begin{array}{l}\text { Employment status, living arrangements, educational level, history } \\
\text { of medication, height and weight, comorbidities, medication use }\end{array}$ & All \\
\hline & Alcohol/drug and substance use, marital status & $\geq 16$ years \\
\hline Global outcome ${ }^{1}$ & $\begin{array}{l}\text { Glasgow Outcome Score [28]: clinician-rated measure of overall } \\
\text { functioning as a result of mental and physical sequelae of the injury }\end{array}$ & All \\
\hline Complications $^{1}$ & Record of complications experienced (such as seizures) [29] & All \\
\hline Employment and education $^{1}$ & Return to or changes in employment and educational status & All \\
\hline Mood $^{1}$ & $\begin{array}{l}\text { Hospital Anxiety and Depression Scale [30]: score of }>11 \text { on the } \\
\text { subscales are used to indicate a moderate to high level of anxiety } \\
\text { and/or depression }\end{array}$ & $\begin{array}{l}\geq 16 \text { years } \\
\text { Plus family member assessment }\end{array}$ \\
\hline $\begin{array}{l}\text { Psychological disorders and } \\
\text { other factors }{ }^{1}\end{array}$ & $\begin{array}{l}\text { Screening for posttraumatic stress disorder using the } \\
\text { Posttraumatic Diagnostic Scale [31] } \\
\text { Two verbally asked questions for depression screening [32], and } \\
\text { the suicidal ideation item from the BDI-II [33] }\end{array}$ & $\geq 16$ years \\
\hline Social support & Duke-UNC Functional Social Support Questionnaire [34] & $\geq 16$ years \\
\hline Memory and attention ${ }^{1}$ & Cognitive Failures Questionnaire [35] & $\geq 16$ years \\
\hline $\begin{array}{l}\text { Rehabilitation } \\
\text { direct and indirect costs }\end{array}$ & $\begin{array}{l}\text { Euro-Qol [36] plus additional information on services received, } \\
\text { home modifications, medication use, loss of productivity, } \\
\text { transportation and readmission to hospital }\end{array}$ & $\begin{array}{l}\text { All } \\
\text { (parent report used } 0-8 \text { years) } \\
\text { Plus family member assessment }\end{array}$ \\
\hline Executive functioning & Behavioural Dyscontrol Scale [37] & $\geq 16$ years \\
\hline Disability $^{1}$ & Disability Rating Scale [38] & $\geq 16$ years \\
\hline \multirow[t]{2}{*}{ Illness perception } & Illness Perception Questionnaire [39] & $\geq 16$ years \\
\hline & $\begin{array}{l}\text { Head Drawing Participants are asked to draw their brain, as a } \\
\text { new way to examine people's perceptions of the extent of the brain } \\
\text { injury [40] }\end{array}$ & All \\
\hline Sleep quality & $\begin{array}{l}\text { The Epworth sleepiness scale [41] and the } \\
\text { Pittsburgh Sleep Quality Index [42] }\end{array}$ & $\begin{array}{l}\text { All } \\
\text { (parent report used } 8-16 \text { years) }\end{array}$ \\
\hline Postconcussive symptoms ${ }^{1}$ & The Rivermead Post Concussion Symptoms Questionnaire [43] & $\begin{array}{l}\text { All } \\
\text { (parent report used } 2-16 \text { years) }\end{array}$ \\
\hline
\end{tabular}


Table 3 (continued)

\begin{tabular}{|c|c|c|}
\hline & & Age range \\
\hline \multirow[t]{2}{*}{ Cognitive abilities $^{1}$} & $\begin{array}{l}\text { CNS Vital Signs test [44]: a computerised test of } 5 \text { basic mental } \\
\text { functions (memory, psychomotor speed, reaction time, complex } \\
\text { attention and cognitive flexibility) }\end{array}$ & $\geq 8$ years \\
\hline & $\begin{array}{l}\text { The Woodcock-Johnson III Tests of Cognitive Abilities (WJ III } \\
\text { COG) [45], a clinical measure of verbal ability, thinking ability, and } \\
\text { cognitive efficiency. }\end{array}$ & $2-8$ years \\
\hline \multirow[t]{2}{*}{ Quality of life ${ }^{1}$} & 36-item Short Form [46] assessing health-related quality of life & $\begin{array}{l}\geq 16 \text { years } \\
\text { Plus family member assessment }\end{array}$ \\
\hline & Paediatric Quality of Life [47] & $\begin{array}{l}8-16 \text { years } \\
\text { (parent report used } 0-8 \text { years) }\end{array}$ \\
\hline Community integration & Community Integration Questionnaire [48] & $\geq 16$ years \\
\hline \multirow[t]{2}{*}{$\begin{array}{l}\text { Adaptive behaviour and } \\
\text { social emotional functioning }\end{array}$} & $\begin{array}{l}\text { Behavioural Assessment System for Children (completed } \\
\text { retrospectively) [49] }\end{array}$ & $2-16$ years \\
\hline & $\begin{array}{l}\text { Adaptive Behaviour Assessment System (2nd edition) }[50]- \\
\text { parent-proxy reports and self-report versions are administered }\end{array}$ & $<16$ years \\
\hline Family burden & Bakas caregiving outcomes scale [51] & Family members only \\
\hline Parent/proxy information & $\begin{array}{l}\text { Relationship to participant, date of birth, gender, current work } \\
\text { situation, care provision for participant }\end{array}$ & All parent/proxy assessments \\
\hline
\end{tabular}

${ }^{1}$ Assessments forming part of the 'short' assessment.

would like to participate in the study. For each case, a family member was also invited to participate. If eligible participants could not be contacted in time to complete the baseline interview, they were contacted again at 1 month to offer them the opportunity to participate. All consenting and eligible TBI participants were assessed at their place of residence or a mutually convenient location (e.g. private room at the local university). Aspects of the assessments could be completed over the telephone if preferred by the participant.

\section{Outcome Data Collection Procedures}

One issue which needed to be addressed at the outset of the study was the cultural context in which the assessments would occur; the breadth of areas to be assessed; when these assessments should occur, and the broad age range to be covered.

All assessments were checked by a cultural advisory committee to ensure that the content was culturally appropriate for the New Zealand multicultural population. In particular, it was important to ensure that the assessments were suitable for Maori and Pacific Island people who are overrepresented in the TBI population [17]. As TBI has a wide range of potential outcomes, different assessments were selected to measure health outcomes including cognitive and neurobehavioral impairments, posttraumatic amnesia, disability, health-related quality of life and community integration (table 3 ). The assessments were delivered by a researcher and took on average $2 \mathrm{~h}$ to complete (these could be completed across two or more sessions if required).

Methodology for Epidemiological Studies in TBI
Another issue was establishing the specific time frame within which participants were to be assessed at each study time point. Due to the closeness of the baseline and 1-month follow-up assessments, baseline assessments began within 2 weeks of the injury. The 1-month assessment could be carried out between 2 and 6 weeks after the injury, ensuring a minimum of 2 weeks occurred between baseline and 1-month assessments. A 4-week window following the assessment date was used in order to ensure better capture of these assessments given the potential for delays in recruitment (e.g. people not realising that they had experienced a TBI until they notice symptoms and seek medical attention). Any assessments occurring outside these time frames were recorded as a protocol violation.

Children were assessed using age-appropriate versions of the questionnaire measures and neuropsychological assessments selected for the study. This required the development of child assessment booklets for use in four age groups: 2 to $<8$ years, 8 to $<12$ years, 12 to $<13$ years and 13 to $<16$ years. A similar procedure was used to develop the corresponding parent assessments $(0$ to $<2$ years, 2 to $<5$ years, 5 to $<6$ years, 6 to $<8$ years, 8 to $<12$ years, 12 to $<13$ years, 13 to $<16$ years). Children who moved into the next age bracket during the follow-up period of the study were administered assessments for their age on the day of the assessment.

All adults (including parents and family members) were screened for anxiety and depression using the Hospital Anxiety and Depression Scale [30], as well as suicide risk (DSM-IV suicide risk items) and posttraumatic stress disorder [31]. Referrals were 
made to the participant's GP or the emergency mental health team if participants were identified as being at immediate risk of harm. If no immediate risk of harm was identified, but high levels of anxiety or depression were recorded, permission was sought for the researcher to contact the participant's GP or health care provider and the study operation group was notified. Children were screened for risk of harm as indicated by the child's or parent's responses to the critical items of the Behavioural Assessment Scale for Children [49]. Critical items were flagged as discussed at the time of the visit and the participant's GP was contacted where this was appropriate. For cases where there was concern that the child was at immediate risk of harm (to others or themselves), a referral was made to the Child Youth and Family Service.

Methods to Support Participant Recruitment and Reduce Attrition

Several sources of bias are possible in assessing incidence, risk factors and outcomes in a study of this type. One of the most important potential biases was loss to follow-up, which may occur in up to $40 \%$ of TBI subjects [52]. To prevent loss to follow-up for the planned 6- and 12-month follow-up assessments, a number of proactive steps were taken.

(1) Collection of relevant contact information at the baseline assessment, including alternative contact addresses and phone numbers, contact address of a parent/grandparent/next of kin and GP. For people who were homeless, these options were often not viable and the only way of making contact with the person was if they were receiving follow-up services through a health care service provider.

(2) Emphasis on the facilitation and building of rapport between the clinical researchers and participants, and where possible, the maintenance of the same research-participant combinations.

(3) Provision of information explaining the importance of the study and need for data on how people with TBI recover over time.

(4) Provision of financial incentives for completion of the followup assessments (20 NZD food/fuel voucher) [52, 53].

(5) Offering a 'shortened' follow-up assessment interview for participants unable to complete the full 2-hour follow-up assessment. This shorter assessment was determined through discussion and consensus of the study Steering Committee who prioritised the outcome assessments based on evidence of their psychometric properties and likelihood to inform health outcomes.

One aspect of implementing a population-based study that was not mentioned in the guidelines was the importance of staff recruitment and retention. The incidence of TBI in the BIONIC study was higher than anticipated and a large team of 8 full-time equivalent research assistants and 1 full-time equivalent study manager per 100,000 residents were required. Some researchers were employed under casual contracts to enable flexible working hours around the varying rates of referrals over the course of the year (as some seasonal variation is evident). Clinical researchers were required to have some health care experience, to attend a 2-day formal training session and were supervised for several weeks to practice administering the assessments, before being allocated their own participant cases. Observation of the researchers conducting interviews, individual feedback on completed paperwork and weekly team meetings have been held throughout the study to ensure consistency of interview delivery and to facilitate understanding of the research study. Ongoing training has been provided to the team in response to issues that have arisen, such as engaging and working with sensitive cases, working with participants experiencing high levels of anxiety and depression, in addition to refresher training on the administration of the assessment measures. All research assistants were provided with a mobile phone to ensure contact with participants whilst working outside of the study offices and for personal safety reasons. An electronic calendar booking system was established to ensure that the study managers were aware of where research assistants were at all times (in case of emergency) and to enable the monitoring of follow-up completion within the specific time frame. Each researcher was also provided with a laptop computer and internet access for the administration and scoring of assessments and to facilitate communication with the broader study group.

Both children and parents were required to complete assessments for participants $<16$ years of age, and this was efficiently managed by two researchers, one to interview and assess the child and one to interview the parent/legal guardian, attending the same assessment appointment. This helped to reduce the difficulties of finding mutually convenient times for the child and parent, engaged the child so a parent/legal guardian could concentrate on the interview and helped to avoid the risk of possible contamination of the data by a parent/legal guardian answering on the child's behalf.

Dedicated data entry staff helped to ensure consistency of data entry. If any information was unclear from the paper record forms, the data entry team contacted the researcher who conducted the assessment for clarification. Range and logic checks helped to identify any missing items and data entry errors. A random sample of $10 \%$ of all forms will be subjected to double entry to ensure consistency between paper forms and the electronic database.

The consent rate in this study (60\% of contactable participants) is lower than rates reported in previous TBI incidence studies which recruited participants through hospital databases [20, 54]. This may reflect the different nature of this community- and hospital-based study population. People with milder TBIs are more likely to integrate back into the community, compared to those experiencing moderate to severe injuries. This may mean that participants are less likely to wish to participate in research, particularly if they are no longer experiencing any symptoms or if they are short of time as they have returned to work. Differences between those who decided to participate and those who do not will be analysed on completion of the study to explore this potential issue further. This population also yielded unique challenges in conducting incidence studies, such as engaging sensitive cases of assault or child abuse in the study, tracking down cases where inaccurate details are recorded and the high numbers of people who were homeless or of transient abode. The use of multiple sources of case ascertainment has proven useful in tracing some of these cases in the community. The low level of attrition to date $(2.54 \%$ at the 1 -month follow-up and $5.07 \%$ at 6 months) indicates that once engaged in the study, participants were willing to complete the follow-up assessment. This suggests that the procedures taken to identify and retain cases in the study are proving to be effective, although further analysis will be required to explore if this trend continues at 1 year. 


\section{Standard Data Presentation}

As specified in the Standard Definitions section of this article, TBI incidence was recorded over a specified 1-year period. As age at injury was collected for each participant in addition to gender, area of residence and date of injury, no issues have arisen in relation to the section on data presentation suggested by the guidelines in table 1. Data will be analysed in accordance with the suggested parameters [12], including 95\% confidence intervals.

\section{Discussion}

The proposed methodology of the study has proven to be feasible, with case ascertainment above the rate predicted, indicating successful identification of TBI cases (results to be published separately). Clear criteria for the inclusion of injuries, obtaining evidence of injury from medical records and panel review of unclear cases, were approaches used to prevent under- or overreporting of injuries. With regard to the recording of prior TBIs which were dependent on self-report (due to lack of reliable recording of TBIs, particularly mild TBIs, in medical notes), there is a risk that over- or underreporting may have occurred and this is acknowledged as a limitation of these data. Refinements to the study protocol made in response to issues arising throughout the implementation of the study, such as conducting $99 \%$ of assessments in participants' homes ( $1 \%$ were conducted with the participants in hospital or residential facility), sending two researchers to conduct the parent and child interviews and providing a shortened assessment for those unable to complete the full assessment in addition to establishing ongoing training and monitoring procedures for staff, having dedicated staff completing the data entry and consulting stakeholders to establish referral pathways and the criteria used (e.g. subclassifying mild TBI), supported the feasibility of study procedures.

Standard TBI severity criteria for children urgently need to be established to ensure that the severity of injury is accurately captured and to enable the comparison of study findings. The use of GCS and PTA scores to classify TBI severity in children has been revealed to be problematic, as GCS scores may overestimate the severity of injury in preverbal children $[55,56]$ and PTA scores may be affected by the cognitive abilities of young children who may not be able to remember the information required for the PTA assessment [57]. Although a paediatric version of the scale is available, the scale is not widely used by health care services so that it can be used to inform population-based studies such as BIONIC. Further investigation into the use of subclassification criteria for mild TBI is also essential to discriminate between the high proportions of these cases to inform the understanding as to why some cases of mild TBI have different outcomes to others with the aim to inform clinical treatment.

The importance of the role of the research staff team is underestimated by current guidelines and suggestions for ensuring consistency of assessment administration and data entry would be beneficial for quality assurance purposes to facilitate population-based studies of TBI worldwide.

\section{Conclusion}

The study thus far has confirmed the feasibility of data collection procedures. However, by reflecting on the suggested guidelines for conducting population-based TBI studies [12], a number of practical issues in implementing these guidelines and suggestions for refining these guidelines have been highlighted, such as setting standard TBI severity criteria for children and subclassification of mild TBI, outlining methods to facilitate consistency within the research team and establishing procedures for the identification of potential cases of TBI not recorded in the patients' medical record. The methodology of the BIONIC study provides a possible framework for future population-based studies of TBI in other developed countries to enable comparison between study findings and to provide more accurate estimates of the incidence of TBI and its burden worldwide.

\section{Acknowledgements}

This study is funded by the Health Research Council of New Zealand (HRC 09/063A). The lead author's position is supported by ABI Rehabilitation Management, NZ. The authors would also like to thank all those who have supported the study through advertising and referring eligible participants, the research assistants working on the BIONIC study and all participants for taking part. Without their contribution this study would not have been possible. 


\section{References}

1 von Holst H: Traumatic brain injury; in Feigin VLB, Bennett DA (eds): Handbook of Clinical Neuroepidemiology. New York, Nova Science Publishers, Inc, 2007, vol 1, pp 197-232.

-2 Langlois JA, Rutland-Brown W, Wald MM: The epidemiology and impact of traumatic brain injury: a brief overview. J Head Trauma Rehabil 2006;21:375-378.

-3 Babikian T, Asarnow R: Neurocognitive outcomes and recovery after pediatric TBI: meta-analytic review of the literature. Neuropsychology 2009;23:283-296.

-4 Donders J, Warschausky S: Neurobehavioral outcomes after early versus late childhood traumatic brain injury. J Head Trauma Rehabil 2007;22:296-302.

5 Temkin NR, Corrigan JD, Dikmen SS, Machamer J: Social functioning after traumatic brain injury. J Head Trauma Rehabil 2009; 24:460-467.

-6 van Velzen JM, van Bennekom CA, Edelaar MJ, Sluiter JK, Frings-Dresen MH: How many people return to work after acquired brain injury? A systematic review. Brain Injury 2009;23:473-488.

7 New Zealand Guidelines Group: The Diagnosis, Acute Management and Rehabilitation of People after Traumatic Brain Injury. Wellington, Accident Compensation Corporation, 2005.

-8 Thurman DJ, Alverson C, Dunn KA, Guerrero J, Sniezek JE: Traumatic brain injury in the United States: a public health perspective. J Head Trauma Rehabil 1999;14:602615.

9 World Health Organization: Injuries in the WHO European Region: Burden, Challenges and Policy Response: Background Paper for the 55th Session of the WHO Regional Committee (RC55). Geneva, World Health Organization, 2005.

10 Cassidy JD, Carroll LJ, Peloso PM, Borg J, von Holst H, Holm L, Kraus J, Coronado VG, WHO Collaborating Centre Task Force on Mild Traumatic Brain Injury: Incidence, risk factors and prevention of mild traumatic brain injury: results of the WHO Collaborating Centre Task Force on Mild Traumatic Brain Injury. J Rehabil Med 2004;43 (suppl):28-60.

11 Torner JC, Schootman M: Epidemiology of closed head injury; in Rizzo M, Tranel D (eds): Head Injury and Postconcussive Syndrome. New York, Churchill Livingstone, 1996.

$\checkmark 12$ Barker-Collo SL, Feigin VL: Capturing the spectrum: suggested standards for conducting population-based traumatic brain injury incidence studies. Neuroepidemiology 2009; $32: 1-3$.
13 Carroll LJ, Cassidy JD, Holm L, Kraus J, Coronado VG: Methodological issues and research recommendations for mild traumatic brain injury: the WHO Collaborating Centre Task Force on Mild Traumatic Brain Injury. J Rehabil Med 2004;113-125.

14 Teasdale G, Jennett B: Assessment of coma and impaired consciousness. A practical scale. Lancet 1974;2:81-84.

15 Ponsford J, Willmott C, Rothwell A, Kelly AM, Nelms R, Ng KT: Use of the Westmead PTA scale to monitor recovery of memory after mild head injury. Brain Inj 2004;18:603614.

16 Shores EA, Marosszeky JE, Sandanam J, Batchelor J: Preliminary validation of a scale for measuring the duration of post-traumatic amnesia. Med J Aust 1986;144:569-572.

17 Barker-Collo SL, Wilde NJ, Feigin VL: Trends in head injury incidence in New Zealand: a hospital-based study from 1997/1998 to $2003 / 2004$. Neuroepidemiology 2009;32: $32-39$.

18 Hoge CW, McGurk D, Thomas JL, Cox AL, Engel CC, Castro CA: Mild traumatic brain injury in US soldiers returning from Iraq. N Engl J Med 2008;358:453-463.

19 Shores EA, Marosszeky JE, Sandanam J, Batchelor J: Preliminary validation of a clinical scale for measuring the duration of posttraumatic amnesia. Med J Aust 1986;144: 569-572.

20 Lin MR, Chiu WT, Chen YJ, Yu WY, Huang SJ, Tsai MD: Longitudinal changes in the health-related quality of life during the first year after traumatic brain injury. Arch Phys Med Rehabil 2010;91:474-480.

21 Servadei F, Teasdale G, Merry G: Defining acute mild head injury in adults: a proposal based on prognostic factors, diagnosis and management. J Neurotrauma 2001;18:657664.

22 Silver JM, McAllister TW, Yudofsky SC: Textbook of Traumatic Brain Injury. Washington, American Psychiatric Publishers, 2005.

23 Statistics New Zealand: New Zealand Census 2006. Wellington, Statistics New Zealand, 2006.

24 Anderson CS, Carter KN, Hackett ML, Feigin V, Barber PA, Broad JB, Bonita R: Trends in stroke incidence in Auckland, New Zealand, during 1981 to 2003. Stroke 2005;36: 2087-2093.

25 Corrigan JD, Selassie AW, Orman JA: The epidemiology of traumatic brain injury. J Head Trauma Rehabil 2010;25:72-80.

26 Simpson DA, Cockington RA, Hanieh A, Raftos J, Reilly PL: Head injuries in infants and young children: the value of the Paediatric Coma Scale. Review of literature and report on a study. Child Nerv Syst 1991;7:183190.
27 Reilly PL, Simpson DA, Sprod R, Thomas L: Assessing the conscious level in infants and young children: a paediatric version of the Glasgow Coma Scale. Child Nerv Syst 1988; 4:30-33.

28 Jennett B, Bond M: Assessment of outcome after severe brain damage. A practical scale. Lancet 1975;305:480-484

29 King N: Mild head injury: neuropathology, sequelae, measurement and recovery. Br J Clin Psychol 1997;36:161-184.

30 Zigmond AS, Snaith RP: The hospital anxiety and depression scale. Acta Psychiatr Scand 1983;67:361-370.

31 Foa E, Cashman L, Jaycox L, Perry K: The validation of a self-report measure of posttraumatic stress disorder: the posttraumatic diagnostic scale. Psychol Assess 1997;9:445451.

32 Kroenke KS, Spitzer RL, Williams JB: The patient health questionnaire-2. Validity of a two-item depression screener. Med Care 2003;41:1284-1292.

33 Beck A, Steer R, Brown G: Beck Depression Inventory Manual, ed 2. San Antonio, The Psychological Corporation, Harcourt, Brace and Company, 1996.

- 34 Broadhead WE, Gehlbach SH, de Gruy FV, Kaplan BH: The Duke-UNC Functional Social Support Questionnaire. Measurement of social support in family medicine patients. Med Care 1988;26:709-723.

35 Broadbent DE, Cooper PF, Fitzgerald P, Parkes KR: The Cognitive Failures Questionnaire (CFQ) and its correlates. Br J Clin Psychol 1982;21:1-16.

36 The EuroQol Group: EuroQol - A new facility for the measurement of health-related quality of life. Health Policy 1990;16:199208.

37 Grigsby J, Kaye K, Robbins LJ: Reliabilities, norms and factor structure of the Behavioral Dyscontrol Scale. Percept Mot Skills 1992;74: 883-892.

38 Hall K, Cope DN, Rappaport M: Glasgow Outcome Scale and Disability Rating Scale: comparative usefulness in following recovery in traumatic head injury. Arch Phys Med Rehabil 1985;66:35-37.

39 Broadbent E, Petrie KJ, Main J, Weinman J: The brief illness perception questionnaire. J Psychosom Res 2006;60:631-637.

40 Petrie KJ, Jago LA, Devcich DA: The role of illness perceptions in patients with medical conditions. Curr Opin Psychiatry 2007;20: 163-167.

41 Johns MW: A new method for measuring daytime sleepiness: the Epworth sleepiness scale. Sleep 1991;14:540-545. 
-42 Buysse DJ, Reynolds CF 3rd, Monk TH, Berman SR, Kupfer DJ: The Pittsburgh sleep quality index: a new instrument for psychiatric practice and research. Psychiatry Res 1989;28:193-213.

-43 King NS, Crawford S, Wenden FJ, Moss NE, Wade DT: The Rivermead Post Concussion Symptoms Questionnaire: a measure of symptoms commonly experienced after head injury and its reliability. J Neurol 1995; 242:587-592.

-44 Gualtieri CT, Johnson LG: Reliability and validity of a computerized neurocognitive test battery, CNS vital signs. Arch Clin Neuropsychol 2006;21:623-643.

45 Woodcock RW, McGrew KS, Mather N: Woodcock-Johnson III Tests of Cognitive Abilities. Itasca, Riverside Publishing, 2001.

$\checkmark 46$ Ware JE, Sherbourne CD: The MOS 36-item short-form health survey (SF-36). 1. Conceptual framework and item selection. Med Care 1992;30:473-483.
47 Varni JW, Seid M, Kurtin PS: Pediatric health-related quality of life measurement technology: a guide for health care decision makers. J Clin Outcomes Manag 1999;6:3340

48 Willer B, Rosenthal M, Kreutzer JS, Gordon WA, et al: Assessment of community integration following rehabilitation for traumatic brain injury. J Head Trauma Rehabil 1993 8:75-87.

49 Reynolds CR, Kamphaus RW: The Clinician's Guide to the Behavior Assessment System for Children (BASC). New York, Guilford Press, 2002.

50 Harrison PL, Oakland T: Adaptive Behaviour Assessment System, ed 2. San Antonio, Harcourt Assessment Inc, 2003.

51 Bakas T, Champion V: Development and psychometric testing of the Bakas Caregiving Outcomes Scale. Nurs Res 1999;48:250 259.

52 Corrigan JD, Harrison-Felix C, Bogner J Dijkers M, Terrill MS, Whiteneck G: Systematic bias in traumatic brain injury outcome studies because of loss to follow-up Arch Phys Med Rehabil 2003;84:153-160.
53 Coen A, Patrick D: Minimizing attrition in longitudinal studies of special populations: an integrated management approach. Eval Program Plann 1996;19:309-319.

54 Langley J, Johnson S, Slatyer M, Skilbeck CE, Thomas M: Issues of loss to follow-up in a population study of traumatic brain injury (TBI) followed to 3 years post-trauma. Brain Inj 2010;24:939-947.

55 Fletcher JM, Ewing-Cobbs L, Miner ME, Levin HS, Eisenberg HM: Variability in Outcomes after Traumatic Brain Injury in Children: A Developmental Perspective. New York, Oxford University Press, 1990.

56 Van Der Voorde P, Sabbe M, Rizopoulus D, DeJaeger A, Lesaffre E, Peters M, PENTA study group: Assessing the level of consciousness in children: a plea for the Glasgow Coma Motor subscore. Resuscitation 2008; 76:175-179.

57 McKinlay A: Controversies and outcomes associated with mild traumatic brain injury in childhood and adolescences. Child Care Health Dev 2010;36:3-21. 